molecules using a cryogenic detector in a matrix-assisted laser desorption/ionization time-of-flight mass spectrometer. Rapid Commun. Mass Spectrom. 10, 1946 (1996).

6. Labov, S. E. et al. Cryogenic detector development at LLNL: ultraviolet, X-ray, gamma-ray and biomolecule spectroscopy. in Proc. 7th Int. Workshop on Low Temperature Detectors (ed. Cooper, S.) 82-95 (Max Planck Institute of Physics, Munich, 1997).

Benner, W. H. et al. Simultaneous measurement of flight time and energy of large matrix-assisted laser desorption ions with a superconducting tunnel junction detector. J. Am. Soc. Mass Spectrom. 8, 10941102 (1997).

8. Mears, C. A. et al. Analysis of pulse shape from a high resolution superconducting tunnel junction Xray spectrometer. Nucl. Instrum. Meth. Phys. Res. A 370, 53-56 (1996).

9. Peacock, A. et al. Single optical photon detection with a superconducting tunnel junction. Nature 381, 135-137 (1996)

10. McCammon, D., Cui, W., Juda, M., Morgenthaler, J. \& Zhang, J. Thermal calorimeters for high resolution X-ray spectroscopy. Nucl. Instrum. Meth. Phys. Res. A 326, 157-165 (1993).

11. Irwin, K. D., Hilton, G. C., Wollman, D. A. \& Martinis, J. M. X-ray detection using a superconducting transition-edge sensor microcalorimeter with electrothermal feedback. Appl. Phys. Lett. 69, 19451947 (1996).

12. Nahum, M. \& Martinis, J. M. Hot-electron microcalorimeters as high-resolution x-ray detectors. Appl. Phys. Lett. 66, 3203-3205 (1995).

13. Martinis, J. M. Hot-electron-microcalorimeters with $0.25 \mathrm{~mm}^{2}$ area. Nucl. Instrum. Meth. Phys. Res. A 370, 171-172 (1996)

14. Welty, R. P. \& Martinis, J. M. A series array of DC SQUIDs. IEEE Trans. Mag. 27, 2924-2926 (1991) 15. Schreiner, M., Strupat, K., Lottspeich, F. \& Eckershorn, C. Ultraviolet matrix assisted laser desorption ionization-mass spectrometry of electroblotted proteins. Electrophoresis 17, 954-961 (1996).

16. Vaney, M. C., Maignan, S., Ries-Kautt, M. \& Ducruix, A. Protein Data Bank File No. 1931 (Brookhaven National Laboratory Protein Data Bank, 1995).

17. Spengler, B., Kirsch, D. \& Kaufmann, R. Fundamental aspects of postsource decay in matrix-assisted laser desorption mass spectrometry. 1. Residual gas effects. J. Phys. Chem. 96, 9678-9684 (1992).

18. He, X. M. \& Carter, D. C. Atomic structure and chemistry of human serum albumin. Nature 358, 209215 (1992)

Correspondence and requests for materials should be addressed to G.H. (e-mail hilton@boulder.nist. gov).

\section{Increased stratospheric ozone depletion due to mountain-induced atmospheric waves}

K. S. Carslaw ${ }^{\star}$, M. Wirth $\dagger$, A. Tsias*, B. P. Luo ${ }^{\star}$, A. Dörnbrack $\dagger$, M. Leutbecher $\dagger$, H. Volkert $\dagger$, W. Renger $\dagger$, J. T. Bacmeister $\ddagger$ E. Reimer $₫ \&$ Th. Peter ${ }^{\star}$

${ }^{*}$ Max-Planck-Institut für Chemie, Postfach 3060, Mainz 55020, Germany $\dagger D L R$, Oberpfaffenhofen, 32230 Wessling, Germany

$\ddagger$ Code 7641, Naval Research Laboratory, Washington DC, 20375, USA

$\$$ Institut für Meteorologie, Carl-Heinrich-Becker Weg, 12165, Berlin 41, Germany

Chemical reactions on polar stratospheric cloud (PSC) particles are responsible for the production of reactive chlorine species (chlorine 'activation') which cause ozone destruction' ${ }^{1}$. Gas-phase deactivation of these chlorine species can take several weeks in the Arctic winter stratosphere, so that ozone destruction can be sustained even in air parcels that encounter PSCs only intermittently ${ }^{2,3}$. Chlorine activation during a PSC encounter proceeds much faster at low temperatures when cloud particle surface area and heterogeneous reaction rates are higher ${ }^{4}$. Although mountain-induced atmospheric gravity waves are known to cause local reductions in stratospheric temperature of as much as $10-15 \mathrm{~K}$ (refs 5-9), and are often associated with mesoscale PSCs ${ }^{10-12}$, their effect on chlorine activation and ozone depletion has not been considered. Here we describe aircraft observations of mountain-wave-induced mesoscale PSCs in which temperatures were $12 \mathrm{~K}$ lower than expected synoptically. Model calculations show that despite their localized nature, these PSCs can cause almost complete conversion of inactive chlorine species to ozone-destroying forms in air flowing through the clouds. Using a global mountain-wave $\operatorname{model}^{8}$, we identify regions where mountain waves can develop, and show that they can cause frequent chlorine activation of air in the Arctic stratosphere. Such mesoscale processes offer a possible explanation for the underprediction of reactive chlorine concentrations and ozone deple- tion rates calculated by three-dimensional models of the Arctic stratosphere $^{13-17}$.

A stratospheric mountain-wave-induced PSC observed by airborne lidar over Scandinavia is shown in Fig. 1a. An ice cloud ('mother-of-pearl cloud') is apparent in the lidar signal as the yellow and red streaks of high aerosol backscatter ratio at around $22 \mathrm{~km}$ altitude. The presence of this cloud indicates strong localized cooling due to mountain-wave activity because the ice frost point at this altitude ( $T_{\text {frost }} \approx 185.7 \mathrm{~K}$ for 5 parts per million by volume, p.p.m.v., water vapour) is considerably lower than the temperature of $193 \mathrm{~K}$ derived from synoptic analyses from the European Centre for Medium-Range Weather Forecasts (ECMWF). The ice cloud is surrounded by a liquid PSC, which is visible in the lidar signal as a distinct wave-disturbed aerosol layer between 21 and $24 \mathrm{~km}$ altitude ${ }^{12}$. This probably formed because of absorption of $\mathrm{HNO}_{3}$ and $\mathrm{H}_{2} \mathrm{O}$ by the background liquid $\mathrm{H}_{2} \mathrm{SO}_{4} / \mathrm{H}_{2} \mathrm{O}$ aerosols ${ }^{18}$. On the day of measurement, the research aircraft made several flights across and parallel to the mountains ${ }^{12}$. All the measurements are consistent with a mountain-induced PSC extending over several hundred kilometres, with dense ice clouds over the highest orography. Analysis of other nearby clouds and of the general mesoscale situation $^{12}$ indicates that the cloud in Fig. 1, including the liquid PSC, was probably embedded in a broader mesoscale minimum temperature.

Here we use data from this short flight segment to demonstrate the potential effect of even such small mesoscale PSCs on stratospheric chemistry. Two features of this flight make it ideal for studying the effect of such clouds on the chemistry of air parcels flowing over the mountains. First, the observation was made by flying directly upwind, which we term quasi-lagrangian. Second, the wave-cloud can be considered as quasi-stationary during the short time required for air parcels to traverse the wave, which is $\sim 30$ minutes. This was confirmed by repeated measurements of other mountain-wave clouds on the same day which revealed quasistationarity on a timescale of $\sim 4$ hours. Also, simulations using the mesoscale model MM5 ${ }^{12}$ indicate that gravity waves in this region were persistent for at least 1 hour. Together, the quasi-lagrangian observation and the stationarity of the cloud allow the particle streaks to be considered as air-parcel trajectories. One such trajectory is indicated by the white line in Fig. 1a, with a temperature shown in Fig. 1c. Thus, the trajectory that we use to study air-parcel microphysics and chemistry was constructed from aerosol layers apparent in the lidar signal, rather than from predictions of the MM5 mesoscale model. Although the MM5 model reproduces very well the general pattern of cooling over the mountains on the day of measurement ${ }^{12}$, resolution limitations mean that the small-scale structure and deep temperature minima apparent in Fig. 1a cannot easily be resolved.

The air-parcel temperature is critical for the microphysical and chemical modelling of the cloud. The existence of ice clearly indicates a departure from synoptic conditions, but the minimum temperature attained in the wave is even lower than the frost point. This minimum temperature can be calculated as follows: at the point of maximum backscatter (point 1 in Fig. 1a) the ice particles are transiently in equilibrium with the gas phase, which implies that the temperature must be below the frost point $\left(T<T_{\text {frost }}\right)$. How much point 1 is below the frost point depends on the amount of water vapour condensed as ice. From our microphysical model simulation, we calculate the actual temperature at point 1 to be $183.8 \pm 0.5 \mathrm{~K}$. Temperatures at other locations in the wave can then be calculated from this reference temperature by assuming dry adiabatic behaviour. The minimum temperature in the wave occurs $\sim 280 \mathrm{~m}$ higher in altitude (point 2 in Fig. 1a) and is therefore $\sim 181 \mathrm{~K}$, some $12 \mathrm{~K}$ lower than synoptic. The rather constant offset of $8-10 \mathrm{~K}$ between the synoptic temperature and the temperature in the wave reflects the fact that the PSC is embedded in a larger mesoscale minimum, and does not indicate a significant warm bias 




Figure 1 Lidar measurements of a mountain-wave PSC. These were made on 15 January 1995 between $67.2^{\circ} \mathrm{N}, 17.2^{\circ} \mathrm{E}$ and $67.5^{\circ} \mathrm{N}, 19.2^{\circ} \mathrm{E}$ from a Transall research aircraft. Also shown is the effect of the cloud on particle growth and chemistry. The time axis refers to an air parcel flowing through the cloud with a wind speed of $45 \mathrm{~m} \mathrm{~s}^{-1}$, as determined from MM5 mesoscale model calculations $^{12}$. a, Backscatter ratio $S$ at 532-nm laser wavelength. b. Calculated $S$ (black line) and observed $S$ (red line) along the trajectory indicated by the white line in $\mathbf{a}$. In terms of the backscatter coefficient, $\beta$, the backscatter ratio $S$ is defined as $S=\left(\beta_{\text {aerosol }}+\beta_{\text {air }}\right) / \beta_{\text {air }}$. Calculations are shown for prolate ice particles with an aspect ratio of 0.95 . c. Air-parcel temperature in the wave and under synoptic conditions as from ECMWF analyses ( $p$ indicates pressure). d, Calculated surface area of liquid aerosols (thin line) and ice (thick line). The timedependent radially resolved liquid aerosol model of Meilinger et al. ${ }^{25}$ was used with nucleation and growth of solid particles included ${ }^{12}$. The model was initialized with liquid particles with 9 p.p.b.v. $\mathrm{HNO}_{3}, 5$ p.p.m.v. total $\mathrm{H}_{2} \mathrm{O}$ and 0.49 p.p.b.v. $\mathrm{H}_{2} \mathrm{SO}_{4}$. All droplets were assumed to freeze as ice $4.1 \mathrm{~K}$ below the ice frost point. e, Chemical trajectory model results in the mountain wave (solid lines). Active chlorine is defined as $\mathrm{Cl}_{x}=\left(2 \times \mathrm{Cl}_{2}\right)+\left(2 \times \mathrm{Cl}_{2} \mathrm{O}_{2}\right)+\mathrm{ClO}$ and is shown also for synoptic conditions (dotted line). The Mainz photochemical box mode ${ }^{26,27}$ was used together with the particle size distributions obtained from the microphysical model. The model was initialized with 1.8 p.p.b.v. $\mathrm{HCl}, 1.2$ p.p.b.v. $\mathrm{ClONO}_{2}, 0.015$ p.p.b.v. $\mathrm{HOCl}$ and no $\mathrm{Cl}_{x}$. in the general synoptic temperature field ${ }^{12}$. A small bias of up to $4 \mathrm{~K}$ in the ECMWF analysed temperatures is possible ${ }^{19}$, but this would not affect our conclusion that the ice cloud in Fig. 1a was caused by strong mesoscale cooling.

A microphysical simulation was performed along the constructed trajectory and the modelled particle sizes were used, together with a light-scattering algorithm ${ }^{12,20}$, to calculate the aerosol backscatter ratio at each position through the cloud (Fig. 1b). The number of ice particles in the cloud was then adjusted to optimize agreement between the calculated and observed backscatter ratio for both polarization channels and both laser wavelengths of 532 and $354 \mathrm{~nm}$. In this case, ice formation appears to have occurred in all of the liquid aerosols ${ }^{12}$, resulting in the relatively large ice-particle surface area shown in Fig. 1d.

We have used a chemical box model to calculate the amount of chlorine activation that occurs in air parcels traversing the wave cloud (Fig. 1e). Particle surface areas in the model were taken from the results of the microphysical simulation, and all important heterogeneous reactions on liquid and ice particles were included ${ }^{21}$. The chemical effect of the ice cloud is clearly apparent, with $\mathrm{ClONO}_{2}$ and $\mathrm{HCl}$ being rapidly converted to reactive chlorine due mainly to the reaction:

$$
\mathrm{ClONO}_{2}+\mathrm{HCl} \rightarrow \mathrm{Cl}_{2}+\mathrm{HNO}_{3}
$$

This chlorine activation is substantial, particularly considering that the ice cloud is only $15 \mathrm{~km}$ long and that the air spends less than 7 minutes in it. Appreciable chemical processing occurs even on the liquid aerosols, showing that ice clouds are not a prerequisite for rapid heterogeneous chlorine activation in mountain-wave events. In combination, liquid and solid chemical processing leads to production of $\sim 1.5$ parts per billion by volume, p.p.b.v., of chlorine in reactive forms (defined here as $\mathrm{Cl}_{x}=\left(2 \times \mathrm{Cl}_{2}\right)+\left(2 \times \mathrm{Cl}_{2} \mathrm{O}_{2}\right)+$

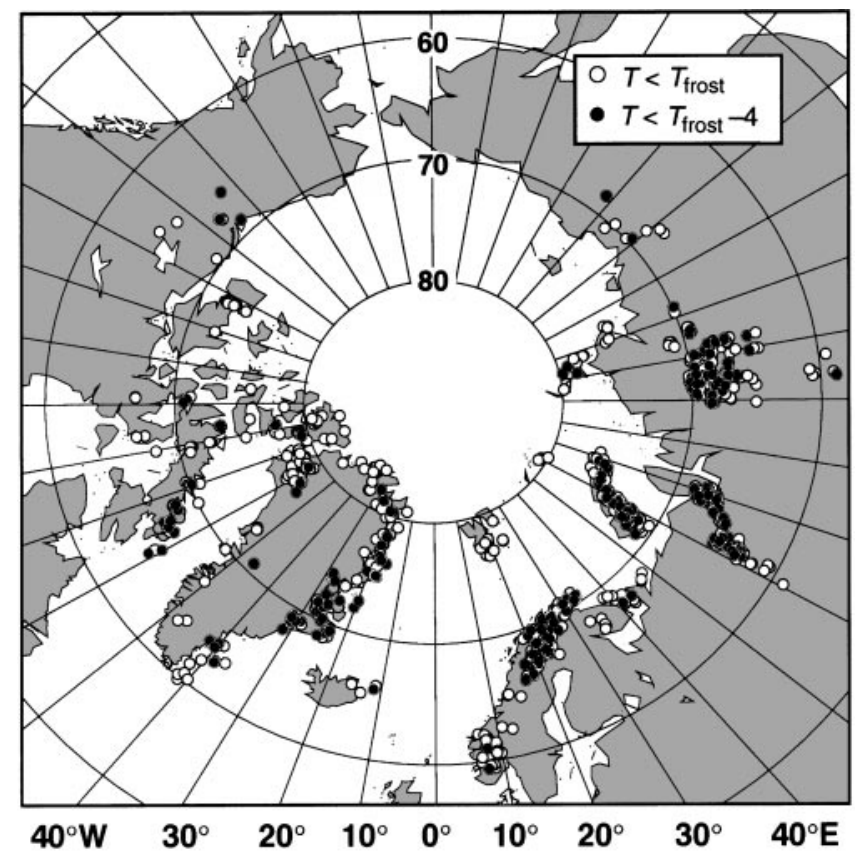

Figure 2 Predicted temperatures reached in mountain waves in the Arctic vortex during December and January 1994-95. Open circles, minimum temperatures lower than the ice frost point ( $T_{\text {frost }}$ ); filled circles, minimum temperatures less than $T_{\text {frost }}-4 \mathrm{~K}$. Calculations were made using synoptic temperatures from ECMWF analyses with mountain-wave cooling calculated using the model of Bacmeister et al. ${ }^{8}$ updated daily. The calculations refer to air which was on the $550 \mathrm{~K}$ potentialtemperature level ( 25 mbar pressure) on 1 December 1994, and which sinks diabatically to $500 \mathrm{~K}$ by 31 January 1995. 
$\mathrm{ClO}$ ), which is almost half of the total inorganic chlorine in the air parcel. This compares with essentially no activation under equivalent synoptic conditions. It is likely that our calculations even underestimate chlorine activation in this case, as they do not include the additional processing that would occur in the larger-scale temperature minimum in which this PSC is embedded. Other PSC observations on this day show mountain-wave-induced liquid PSCs covering $200 \mathrm{~km}$, and ice clouds as long as $30 \mathrm{~km}$. Heterogeneous chlorine activation is complete after a single passage through these clouds. We have also examined the effect of the cloud in Fig. 1a for late-winter conditions where $\mathrm{ClONO}_{2}$ is the principal reservoir species, with very little $\mathrm{HCl}$. Chlorine activation then occurs mainly via the heterogeneous reaction

$$
\mathrm{ClONO}_{2}+\mathrm{H}_{2} \mathrm{O} \rightarrow \mathrm{HOCl}+\mathrm{HNO}_{3}
$$

followed by photolysis of $\mathrm{HOCl}$ to yield $\mathrm{Cl}$ atoms. Heterogeneous loss of $\mathrm{ClONO}_{2}$ was found to be comparably fast.

We have assessed the global significance of such events using a mountain-wave prediction model ${ }^{8}$. This model uses a global database of topographic features containing estimates of ridge height, width and orientation. A two-dimensional hydrostatic wave model driven by $5^{\circ} \times 2^{\circ}$ global analyses of wind and temperature at standard pressure levels is used to calculate the adiabatic cooling above each ridge element. Maximum calculated vertical air-parcel displacements over northern Norway on the day of this PSC observation are between 1,000 and $2,000 \mathrm{~m}$, equivalent to a $10-$ $20 \mathrm{~K}$ change in temperature and comparable to the observed $12 \mathrm{~K}$ cooling derived from Fig. 1 via arguments based on microphysical

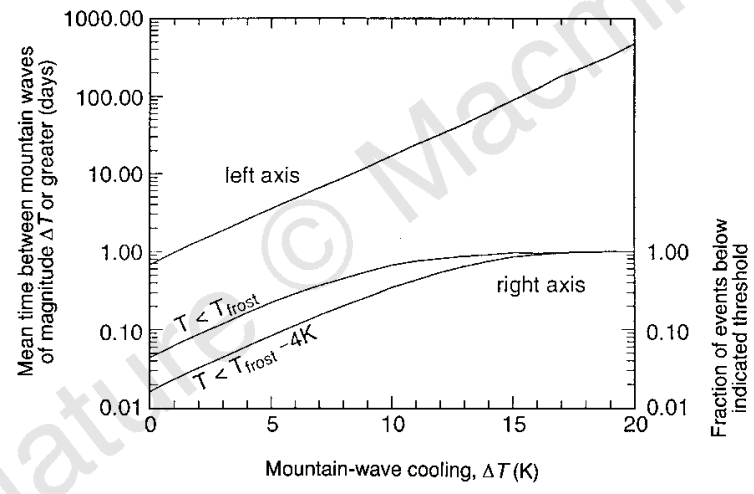

Figure 3 The frequency of occurrence of mountain-wave cooling events. Shown is the frequency with which mountain-wave cooling events greater than a given magnitude $(\Delta T)$ were encountered by air parcels confined within the Arctic polar vortex during December and January 1994-95. The results are shown as the mean time between mountain-wave events of magnitude $\Delta T$ or greater (upper curve, left axis) and the fraction of there events that lead to temperatures less than $T_{\text {frost }}$ and $T_{\text {frost }}-4 \mathrm{~K}$ (lower curves, right axis). The simulation was performed using 190 initially evenly distributed vortex-filling trajectories initialized at $550 \mathrm{~K}$ potential temperature ( $\approx 25$ mbar pressure) on 1 December 1994. Air parcels were advected using ECMWF analysed winds, sinking diabatically to $\sim 500 \mathrm{~K}$ by 31 January 1995. All trajectories remained evenly distributed within the vortex. Temperature excursions in mountain waves were calculated according to Bacmeister et al. ${ }^{8}$ and were updated daily. The calculations refer to 16,934 wave events. The temperature excursion experienced by an air parcel is a function of the closest distance of approach to a ridge. This function is assumed here to be $\Delta T=\Delta T_{\max } \exp \left[-(X / W)^{2}\right]$ downwind of the ridge and $\Delta T_{\max } \exp \left[-10(X / W)^{2}\right]$ upwind, where $x$ (in $\mathrm{km}$ ) is the distance from the ridge line in a cross-ridge direction, $w$ (in $\mathrm{km}$ ) is the cross-ridge width and $\Delta T_{\max }$ is the temperature change at the peak of the disturbance. This influence function represents a plausible wave-amplitude envelope close to a ridge, with most wave energy downstream. The temperature change is assumed to be zero to the left and right of the ridge. processes. We have also examined PSC observations over Scandinavia from January 1997. These revealed ice PSCs consistent with mesoscale cooling of up to $19 \mathrm{~K}$, with the MM5 model results suggesting mesoscale temperatures as much as $15 \mathrm{~K}$ lower than synoptic. Comparison between events such as these and the mountain-wave prediction model suggest reasonable agreement, though further efforts are needed to assess the model reliability for smaller waves.

To assess the potential effect of mountain waves for the Arctic stratosphere as a whole, we have calculated the distribution of mountain-wave cooling events within the Arctic vortex of each day of December 1994 and January 1995. We examined events that were large enough to cause significant chlorine activation - those where temperatures were forced below $T_{\text {frost }}$ and below $T_{\text {frost }}-4 \mathrm{~K}$ (assumed to be sufficient for ice formation)-see Fig. 2. Most such events are concentrated over Norway, East Greenland and the Urals where low synoptic temperatures coincide with strong mountain-wave activity. Figure 3 shows the frequency with which mountain-wave cooling events of a given magnitude are encountered by air parcels confined within the polar vortex, as derived from diabatic synoptic trajectory calculations. Cooling events as large as shown in Fig. $1(\Delta T \geqslant 12 \mathrm{~K})$ occur once every 30 days in a given air parcel, and $\sim 75 \%$ of such events are calculated to lead to temperatures less than $T_{\text {frost }}$. Overall, temperatures in mountain waves are calculated to fall below $T_{\text {frost }}$ approximately once every 17 days in a given air parcel, and below $T_{\text {frost }}-4 \mathrm{~K}$ once every 40 days. For the altitude level we investigated, half of the vortex air was processed below the ice frost point by 20 December, while synoptic temperatures never fell this low.

Further chemical box model calculations (not shown) reveal that the air leaving the mountain-wave PSC shown in Fig. 1 would have continued with elevated reactive chlorine concentrations for as long as 30 days, resulting in as much as $25 \%$ ozone loss in the air parcel even in the absence of further heterogeneous processing. Clearly, from the calculations shown in Fig. 3, repeated re-activation in mountain waves is likely within this time and will lead to a prolonging and intensification of the chlorine activation due to synoptic-scale PSCs. Several earlier modelling studies ${ }^{2,3}$ have highlighted the way in which Arctic chlorine activation and ozone destruction can be sustained by a series of relatively short-lived synoptic PSC events followed by slow reconversion of reactive chlorine species to the reservoir gases. However, in these earlier studies the time available for heterogeneous chlorine activation was of the order of a day, and thus considerably longer than the few minutes exposure to PSCs available in the mountain waves considered here. Mesoscale cooling events will be much more important in the Arctic than the Antarctic because complete chlorine activation in the Arctic due to synoptic-scale PSCs alone is uncommon, and is usually limited to a short period in mid-winter. During cold Arctic winters, such as 1994-95 studied here, the greatest effect is likely to be a prolonging of high active chlorine levels before and after the coldest periods, whereas during warmer winters the waves will induce a general increase in active chlorine concentrations through the whole winter. In both cases gravity waves will lead to enhanced ozone loss.

Several studies have indicated that chemical processing on synoptic-scale PSCs may be insufficient to explain observations of active chlorine and ozone loss in the Arctic, and a number of explanations have been proposed. Lutman et al. ${ }^{13}$ have shown that the geographical extent and peak concentrations of modelled $\mathrm{ClO}$ in the Arctic during 1991-92 were persistently lower than measured by the satellite-borne Microwave Limb Sounder (MLS). Bell et al. ${ }^{14}$ also report a model underprediction of $\mathrm{ClO}$ for the winter 1994-95, while Douglass et al. ${ }^{15}$ found that the early onset of elevated $\mathrm{ClO}$ levels observed by MLS during December 1991 could be reproduced in their model only by reducing synoptic temperatures by $2 \mathrm{~K}$ overall. 
Consistent with low modelled reactive chlorine concentrations, several workers report model underpredictions of ozone depletion of between 25 and $40 \%$ (refs 16,17), although these discrepancies may be due partly to incorrectly modelled gas-phase reactions rather than heterogeneous processing. Edouard et al. ${ }^{22}$ have suggested that such underprediction by three-dimensional models may be caused by averaging small-scale structure in species concentration over large grid boxes. This arises because of the nonlinear dependence of key reaction rates on concentration. This offers a possible explanation for underpredicted ozone loss in three-dimensional models, but does not explain low modelled $\mathrm{ClO}$ and does not refer to predictions of trajectory models ${ }^{13}$. Whether uncertainties in the temperature fields used in models are responsible for model underpredictions $^{13,15}$, or whether the mountain-wave activation mechanism suggested here is inappropriate can only be assessed by undertaking a multi-year model simulation and comparison with available data. However, it should be noted that mountain waves can act as a continuous source of inhomogeneities in reactive chlorine concentrations on a scale of a few kilometres, which, according to the findings of Edouard et al. ${ }^{22}$, will make their inclusion in three-dimensional models highly problematic.

Other sources of gravity waves should also be examined for their potential role in chlorine activation; $\mathrm{Wu}$ and Waters ${ }^{23,24}$ have shown from satellite data that there is evidence for middle-atmosphere gravity waves that correlate not only with surface topography but also with upper-tropospheric convection and stratospheric polar vortices. Gravity waves occurring at the vortex edge should also be examined for their potential contribution to the general decrease in ozone which has been observed at middle latitudes over the past decade $^{1}$.

Received 30 July 1997; accepted 8 January 1998

1. Scientific Assessment of Ozone Depletion: 1994 (Rep. No. 37, World Meteorological Organisation, Geneva, 1994).

2. Jones, R. L., McKenna, D. S., Poole, L. R. \& Solomon, S. On the influence of polar stratospheric cloud formation on chemical composition during the 1988/89 Arctic winter. Geophys. Res. Lett. 17, 545-548 (1990).

McKenna, D.S. et al. Calculations of ozone destruction during the 1988/89 Arctic winter. Geophys. Res. Lett. 17, 553-556 (1990).

4. Borrmann, S. et al. Heterogeneous reactions on stratospheric background aerosols, volcanic sulfuric acid droplets, and type I polar stratospheric clouds. J. Geophys. Res. 102, 3639-3648 (1997).

5. Gary, B. L. Observational results using the microwave temperature profiler during the Airborne Antarctic Ozone Experiment. J. Geophys. Res. 94, 11223-11231 (1989).

6. Volkert, H. \& Intes, D. Orographically forced stratospheric waves over northern Scandinavia. Geophys. Res. Lett. 19, 1205-1208 (1992).

7. Leutbecher, M. \& Volkert, H. Stratospheric temperature anomalies and mountain waves: A three dimensional simulation using a multi-scale weather prediction model. Geophys. Res. Lett. 23, 3329_ 3332 (1996)

8. Bacmeister, J. T., Newman, P. A., Gary, B. L. \& Chan, K. R. An algorithm for forecasting mountain wave-related turbulence in the stratosphere. Weath. Forecst. 9, 241-253 (1994).

9. Dörnbrack, A., Leutbecher, M., Volkert, H. \& Wirth, M. Mesoscale forecasts of stratospheric mountain waves. Meteorol. Applic. (in the press).

10. Stanford, J. L. \& Davis, J. S. A century of stratospheric cloud reports: 1870-1972. Bull. Am. Meteorol. Soc. 55, 213-219 (1974).

11. Peter, Th., Müller, R., Drdla, K., Petzoldt, K. \& Reimer, E. A microphysical box model for EASOE Preliminary results for the January/February 1990 PSC event over Kiruna. Ber. Bunsenges. Phys. Chem. 96, 362-367 (1992).

12. Carslaw, K. S. et al. Particle microphysics and chemistry in remotely observed mountain polar stratospheric clouds. J. Geophys. Res. (in the press).

13. Lutman, E. R. et al. Three-dimensional studies of the 1991/92 northern hemisphere winter using domain-filling trajectories with chemistry. J. Geophys. Res. 102, 1479-1488 (1997).

14. Bell, W. et al. Measurements of stratospheric chlorine monoxide ( $\mathrm{ClO}$ ) from ground-based FTIR observations. J. Atmos. Chem. 24, 285-297 (1996).

15. Douglass, A. et al. A three-dimensional simulation of the early winter distribution of reactive chlorine in the north polar vortex. Geophys. Res. Lett. 20, 1271-1274 (1993).

16. Goutail, F. et al. in Polar Stratospheric Ozone (eds Pyle, J. A., Harris, N. P. \& Amanatidis, G. T.) 574-579 (Air Pollution Res. Rep. No. 56, European Communities, Brussels, 1996).

17. Hansen, G., Svenøe, T., Chipperfield, M. P., Dahlback, A. \& Hoppe, U.-P. Evidence of substantia ozone depletion in winter 1995/96 over northern Norway. Geophys. Res. Lett. 24, 799-802 (1997).

18. Carslaw, K. S., Peter, Th. \& Clegg, S. L. Modeling the composition of liquid stratospheric aerosols Revs. Geophys. 35, 125-154 (1997)

19. Knudsen, B. M. Accuracy of Arctic stratospheric temperature analyses and the implications for the prediction of polar stratospheric clouds. Geophys. Res. Lett. 23, 3747-3750 (1996)

20. Mishchenko, M. I. Light scattering by randomly oriented axially symmetric particles. J. Opt. Soc. Am 8, 871-882 (1991)

21. DeMore, W. et al. Chemical Kinetics and Photochemical Data for Use in Stratospheric Modeling (Publ 97-4, Jet Propulsion Lab., Pasadena, 1997).

22. Edouard, S., Legras, B., Lefevre, F. \& Eymard, R. The effect of small-scale inhomogeneities on ozone depletion in the Arctic. Nature 384, 444-447 (1996).

23. Wu, D. L. \& Waters, J. W. Gravity-wave-scale temperature fluctuations seen by the UARS MLS Geophys. Res. Lett. 23, 3289-3292 (1996)
24. Wu, D. L. \& Waters, J. W. Satellite observations of atmospheric variances-a possible indication of gravity waves. Geophys. Res. Lett. 24, 3631-3634 (1996)

25. Meilinger, S. K. et al. Size-dependent stratospheric droplet composition in lee wave temperature fluctuations and their potential role in PSC freezing. Geophys. Res. Lett. 22, 3031-3034 (1995).

26. Müller, R. et al. Chlorine chemistry and the potential for ozone depletion in the Arctic stratosphere in the winter 1991/92. Geophys. Res. Lett. 21, 1427-1430 (1994).

27. Carslaw, K. S., Peter, Th. \& Müller, R. Uncertainties in reactive uptake coefficients for solid stratospheric particles-2. Effect on ozone depletion. Geophys. Res. Lett. 24, 1747-1750 (1997).

Acknowledgements. We thank M. Mishchenko for help with the T-matrix calculations. Part of this work was funded by the European Communities, the German BMBF, the Office of Naval Research (ONR) and NASA's Atmospheric Chemistry Modeling and Analysis Program (ACMAP).

Correspondence and requests for materials should be sent to K.S.C. (e-mail: carslaw@mpch-mainz. mpg.de).

\section{Reduced sensitivity of recent tree-growth to temperature at high northern latitudes}

\section{K. R. Briffa*, F. H. Schweingruber†, P. D. Jones*,} T. J. Osborn $*$, S. G. Shiyatov $¥ \&$ E. A. Vaganov $\$$

${ }^{*}$ Climatic Research Unit, University of East Anglia, Norwich NR4 7TJ, UK $\dagger$ Swiss Federal Institute of Forest, Snow and Landscape Research,

Zürcherstrasse 111, CH-8903, Birmensdorf, Switzerland

$¥$ Institute of Plant and Animal Ecology, Ural Branch of the Russian Academy of Sciences, 8 Marta Street, Ekaterinburg 620219, Russia

$\$$ Institute of Forest, Siberian Branch of the Russian Academy of Sciences, Krasnoyarsk, Russia

Tree-ring chronologies that represent annual changes in the density of wood formed during the late summer can provide a proxy for local summertime air temperature ${ }^{1}$. Here we undertake an examination of large-regional-scale wood-density/air-temperature relationships using measurements from hundreds of sites at high latitudes in the Northern Hemisphere. When averaged over large areas of northern America and Eurasia, tree-ring density series display a strong coherence with summer temperature measurements averaged over the same areas, demonstrating the ability of this proxy to portray mean temperature changes over sub-continents and even the whole Northern Hemisphere. During the second half of the twentieth century, the decadal-scale trends in wood density and summer temperatures have increasingly diverged as wood density has progressively fallen. The cause of this increasing insensitivity of wood density to temperature changes is not known, but if it is not taken into account in dendroclimatic reconstructions, past temperatures could be overestimated. Moreover, the recent reduction in the response of trees to air-temperature changes would mean that estimates of future atmospheric $\mathrm{CO}_{2}$ concentrations, based on carbon-cycle models that are uniformly sensitive to high-latitude warming, could be too low.

We have based this analysis on tree-growth data derived from trees sampled at more than 300 locations spread across the Northern Hemisphere (Fig. 1). These generally cool and moist sites were all chosen at relatively high latitudes or high elevations for the potential sensitivity of year-by-year tree growth to local temperature variability $^{2}$. Though many of the sites are not strictly at tree-line, these data are a good proxy for the growth of the northern part of the boreal forest, rather than the large areas of closed-canopy, more drought-sensitive southern coniferous forests. Ring widths and the densities of the parts of the rings formed in late summer (maximum-latewood ring densities) were measured using multiple tree cores from each site ${ }^{1}$. The measurement series were then individually detrended to remove inherent age-related bias, by taking residuals from a simple function fit to the raw data and the resulting dimensionless indices averaged to form separate ring-width and 